\title{
Patient Preference for Light-Cured Composite Bite Splint Compared to Heat-Cured Acrylic Bite Splint*
}

\author{
Alden M. Leib
}

Background: Heat-cured acrylic has been the most commonly used material for construction of bite splints. Although effective, its processing involves several steps and is time consuming. Furthermore, acrylic splints distort easily if not kept in water when not worn for long periods of time. A newly developed light-cured composite material is now being used for bite splint fabrication. The composite material offers benefits in ease and speed of construction, has minimal warping and distortion, and has proven patient acceptance. The aim of this study was to determine if patient satisfaction with the composite splint was as good as, or preferential to, the acrylic splint.

Methods: Both a composite and an acrylic bite splint were fabricated for each of 10 patients. The splints were worn alternately on a nightly basis and were adjusted as needed after the first week. After 3 weeks, each patient completed a questionnaire regarding the properties of each splint and any preferences they had in reference to fit, comfort, and other parameters of satisfaction.

Results: All of the patients were able to wear at least one of the splints comfortably. All 10 preferred the composite splint over the acrylic splint, agreeing that it felt more natural and was more comfortable to wear.

Conclusions: The light-cured composite bite splint is preferable from the patient's perspective to the heatcured acrylic bite splint. The composite splint is rapidly constructed on the original model, easily seated, and comfortably worn. Other properties of composite material also make it preferable for longterm use. Future studies are necessary to evaluate the functional differences between the composite and acrylic splint. J Periodontol 2001;72:1108-1112.

\section{KEY WORDS}

Acrylic resins; comparison studies; composite resins; occlusal splints; patient satisfaction.

\footnotetext{
* Private practice, Farmington Hills, MI; Department of Periodontics/ Prevention/Geriatrics, University of Michigan School of Dentistry, Ann Arbor, MI.
}

The need for an occlusal bite splint for the treatment of temporomandibular disorders (TMD) and the control of traumatic occlusal habits has been well documented in the literature. ${ }^{1-6}$ Many clinicians have suggested that the bite splint may be of benefit in protecting against potential damage from traumatic occlusion and occlusal habits, ${ }^{7,8}$ as a retainer following orthodontic therapy, $7,9,10$ as an adjunct to occlusal adjustment, and following extensive restorative dentistry. ${ }^{11,12}$

Recent developments in light-cured composite material for the construction of the bite splint have resulted in a splint that is more rapidly constructed, more easily fitted and delivered, and more comfortably worn. ${ }^{7}$ Many of the unique and beneficial properties of composite that make it suitable for restorative procedures also prove it to be a superior material for the bite splint. ${ }^{7}$

The use of light-cured composite material rather than heat-cured acrylic in the construction of an occlusal splint provides advantages to the dentist, the patient, and the laboratory technician. Preliminary use of the light-cured composite splint in a pilot study suggested that the composite splint is more comfortably worn by the patient and its acceptance and compliance are better when compared to the heat-cured acrylic splint. ${ }^{7}$

This clinical study was designed to evaluate patients' responses to both the light-cured composite and the heat-cured acrylic bite splint. The patients were followed over a 3-week period to determine their ability to wear a bite splint and if there was a preference of one material over the other. After 3 weeks of alternating the composite and acrylic splints, a questionnaire was given to each patient to identify the preferred splint and to assess their perception of how the splint felt and what purposes the splint served.

\section{MATERIALS AND METHODS}

\section{Patient Selection}

Ten patients from a private practice ( 5 males, 5 females; age range 29 to 59 years; median 47 years) were selected to participate in this study. All patients were evaluated and diagnosed for clenching habits and occlusal or incisal wear due to bruxism. Four 
patients had been treated for TMD and bite splints were indicated to control occlusal habits which had caused facial pain, headaches, and restricted occlusal function. Five patients who had been treated for generalized moderate to severe periodontitis persisted in their clenching habits and exhibited secondary trauma from occlusion. Each of these patients had at least 3 teeth with grade 1 or grade 2 mobility and was receiving periodontal maintenance care. One patient was a bruxer and showed extensive occlusal and incisal wear, which had been progressing over the past several years.

Three patients had successfully worn an acrylic splint in the past. These splints no longer fit or had been broken. One patient was still wearing an acrylic splint made 7 years prior to this study.

All patients agreed to participate and signed a treatment consent form. Exclusion criteria for this study included current use of removable appliances; active periodontitis; and Class III molar occlusions.

\section{Splint Fabrication}

A silicon impression of the arch on which the occlusal splint would be constructed was taken and 2 identical models were poured from the impression with a hard die stone. All splints were fabricated from the maxillary model. An alginate impression was taken of the opposing arch and poured immediately with a hard die stone. One wax bite registration was taken in centric relation and used for articulation of the cast models. A simple hinge articulator was used for the mountings.

All splints were constructed as patients were added to the test group over a 2 -week period. Once the technician received a set of models, the fabrication process began for that patient's bite splints. Each patient received one light-cured composite (LCC) ${ }^{\dagger}$ and one heat-cured acrylic (HCA) splint for evaluation. Each LCC splint was constructed utilizing a U-shaped splint "preform" (Fig. 1) made of a light curable octodecyl methacrylate composite. ${ }^{13}$ The precured preform is sufficiently plastic and flowable to be hand contoured over the dental model and trimmed to the desired dimensions (Fig. 2).The composite splint was then placed in a light curing unit until hardened. The HCA splints were made of methyl-methacrylate, which replaced an invested wax pattern of the splint, and then heat cured for 12 hours under pressure in a hot water bath.

The same dental technician constructed both a composite and acrylic splint for each patient (Figs. 3 and 4). Every effort was made to construct both

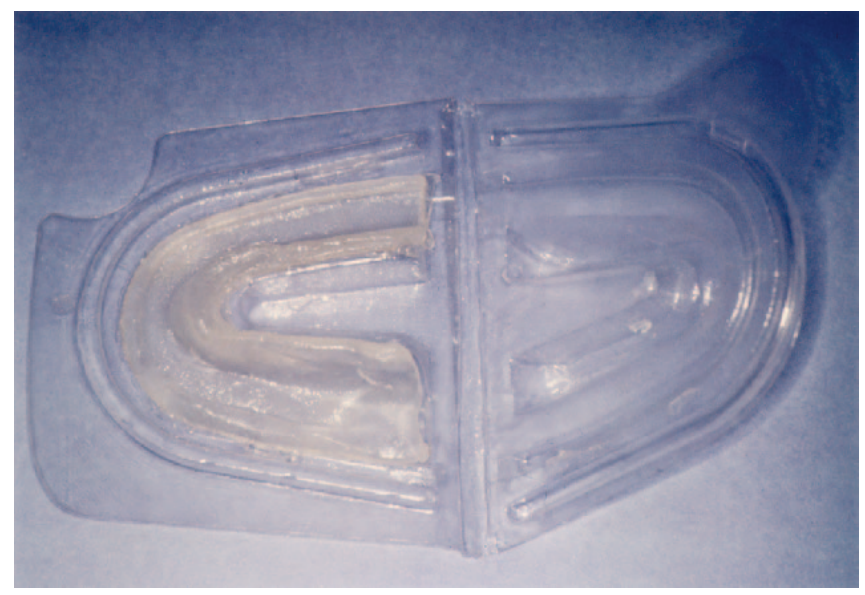

Figure I.

The packaged U-shaped composite "preform" prior to adaptation on the model.

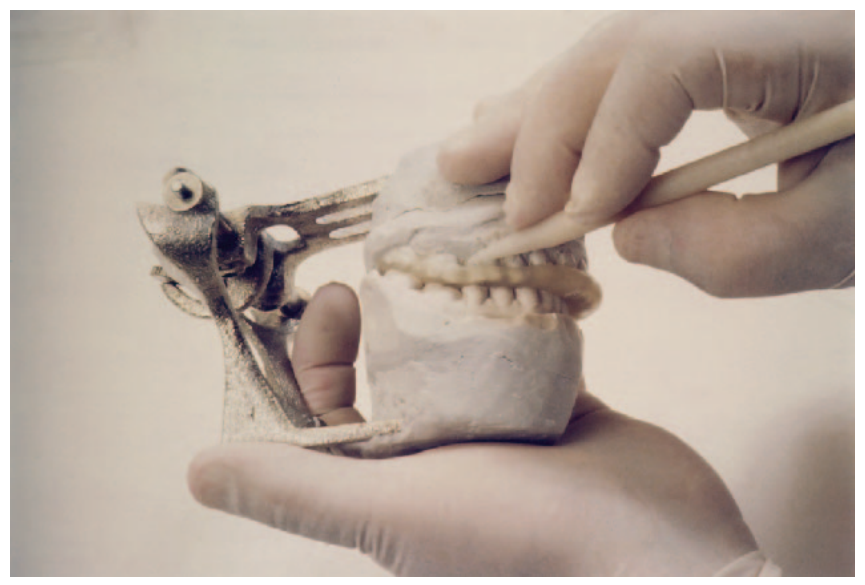

Figure 2.

Composite "preform" molded to a study model and trimmed.

splints with the most similar dimensions, extensions, and incisal overlap. The same dentist seated and adjusted both splints on each patient to assure that the fit of both splints was similar.

\section{Patient Compliance}

Each patient was instructed to wear the splints on an alternating basis, switching every night for 8 days. The LCC splint was worn on even-numbered dates and the HCA splint on odd-numbered dates. After 8 days, the dentist made any necessary adjustments on both splints to assure they fit accurately and com-

† Quicksplint, Moore Technology, Dearborn, MI. 


\section{Case Series}

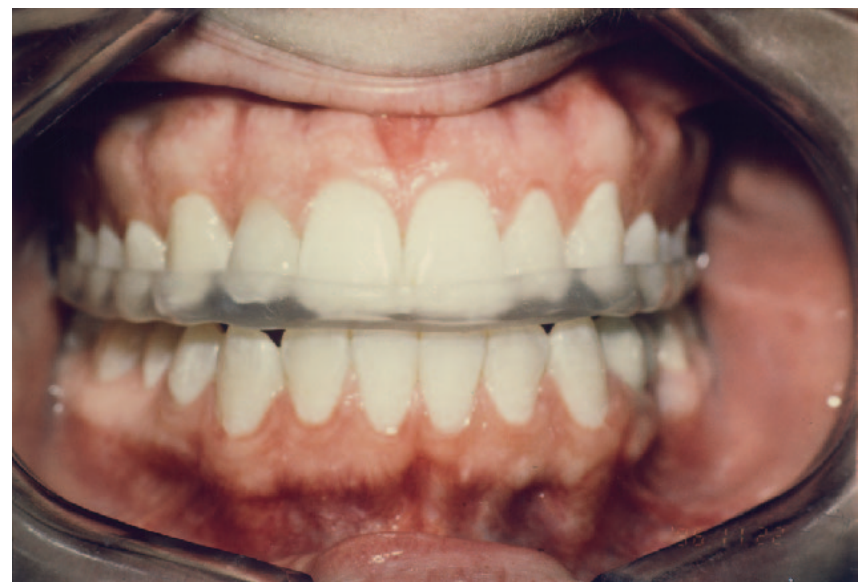

Figure 3.

A light-cured composite bite splint seated, displays its translucent, tooth-colored properties.

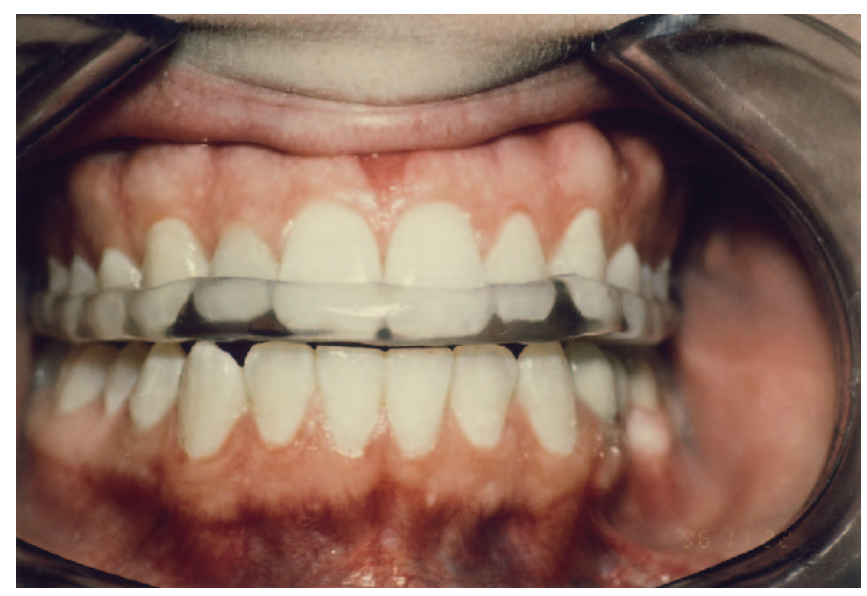

Figure 4.

A heat-cured acrylic bite splint, seated on the same patient as in Figure 3, shows the clear, transparent appearance of acrylic material.

fortably. These adjustments included relieving undercuts in tight-fitting areas, reducing high spots in centric relation, and allowing freedom of movement in all excursions. The patients continued to alternate splints for 2 more weeks. They were then seen to have each splint evaluated and were given a questionnaire to complete.

\section{RESULTS}

All 10 patients who participated in this study were able to wear their splints comfortably and all preferred the composite splint to the acrylic. Table 1 shows the collective responses of the patients to the questionnaire, and reflects some of the feelings
Table I.

\section{Questionnaire and Responses}

\begin{tabular}{l|c|c}
\hline & Yes & No \\
\hline $\begin{array}{l}\text { I. Is the acrylic (HCA) splint more comfortable? } \\
\text { 2. Is the composite (LCC) splint more }\end{array}$ & 0 & 10 \\
comfortable? & 10 & 0 \\
3. Is neither splint comfortable? & 0 & 10 \\
4. The more comfortable splint can best & & \\
be described as (check all correct statements) & & \\
a. It feels more natural. & 10 & \\
b. It fits on my teeth more comfortably. & 8 & \\
c. It can be worn throughout the night. & 10 & \\
d. The splint keeps my teeth apart. & 7 & \\
e. The splint keeps me from clenching my teeth. & 8 & \\
f. The splint feels comfortable when seated. & 10 & \\
\hline
\end{tabular}

patients had regarding the occlusal bite splint. Four of the patients had worn an acrylic splint comfortably prior to this study. In these cases, also, both a new acrylic and a composite splint were made for comparative evaluation. These 4 patients participated in this project because their previous splint was either lost or broken or it no longer fit due to newly placed dental restorations.

The questionnaire showed that all patients found at least one of the splints to be comfortable and all of the patients were able to wear one or both splints throughout the night. All patients acknowledged that the composite splint felt "more natural." Patients reported compliance to the advised protocol of alternating the appliances every other night.

Six of the patients in this study have continued as patients in the same practice since the study was undertaken in 1997. Three of these patients were initially treated for TMD and continued to wear the composite bite splint comfortably and with no recurrence of TMD symptoms. Two patients had been treated for periodontitis, clenching, and secondary trauma from occlusion. They also continued to wear their composite splint and displayed no increase in tooth mobility. One patient required maxillary restorative dentistry and a new bite splint was indicated. Another composite splint was made for this patient and has been worn comfortably for over 1 year. 


\section{DISCUSSION}

All the splints in this study (composite and acrylic) were constructed in a similar manner as described in several studies. ${ }^{10-15}$ They were all rigid ${ }^{16-18}$ and provided full coverage over all the occlusal surfaces. There was point contact in centric relation with all the opposing teeth and freedom of movement in all excursions. The splints did not allow for any irreversible changes in the occlusion or in the temporomandibular joint. $7,11,19$

The unanimous opinion of the patients in this study was that the composite splint is favorable to the acrylic splint. The questionnaire (Table 1) also attempted to discern how the patient viewed the splint and what they perceived the value of the splint to be. Researchers ${ }^{10}$ have instructed their patients at splint delivery to not bite down on the splint. It is felt that the patient should be informed that the splint is not designed to provide an occlusal surface, but rather is a device that interrupts and negates the occlusion.

All the patients agreed that when they attempted to occlude their teeth, the interfering splint caused them to open slightly. After continued attempts to bring their teeth together, muscle memory developed, allowing them to sleep comfortably with the teeth apart. However, we could not confirm this response in patients with nocturnal bruxism.

The features and properties of composite materials (Table 2) may explain the patients' preference for the composite, which can be constructed on the original model and therefore does not require duplication of the cast. This step reduces the fabrication time and eliminates the possibility of distortion. If there is a light curing unit in the office, the composite splint can be designed on the model, light cured in $90 \mathrm{sec}-$ onds to 10 minutes (depending on the intensity of the light in the curing unit) trimmed, and seated within 30 minutes.

The composite has been proven an excellent material for restorative dentistry and its properties most compatible and similar to natural tooth structure. ${ }^{20}$ The natural and comfortable feeling that the patients attributed to the composite splint may be due to its tooth-like properties, especially its degree of hardness and the resonance of the material. ${ }^{7}$

Composite is not a hydrophilic material, as is acrylic. Therefore, composite splints do not absorb oral stains and odors. If not worn for any length of time, acrylic splints not kept in water will warp and distort. This is not so with composite splints. ${ }^{13,21,22}$

Some investigators have complained that the color
Table 2.

Features and Properties of the LightCured Composite and the Heat-Cured Acrylic Splint

\begin{tabular}{l|ll}
\hline & \multicolumn{1}{c}{ Composite } & \multicolumn{1}{c}{ Acrylic } \\
\hline Construction & $\begin{array}{l}\text { Made on original } \\
\text { model }\end{array}$ & $\begin{array}{c}\text { Made on duplicated } \\
\text { model }\end{array}$ \\
Construction time & 30 minutes, in office & $\begin{array}{c}\text { I to } 3 \text { weeks, in } \\
\text { lab }\end{array}$ \\
Properties & Tooth-like comfort & "Foreign" feeling \\
Relines & $\begin{array}{l}\text { Light-cured composite } \\
\text { Cold-cured composite }\end{array}$ & Cold-cured acrylic \\
Shrinkage & 2 to 3\% & Up to I7\% \\
Distortion & Not hydrophilic & Hydrophilic \\
Color & $\begin{array}{l}\text { Tooth colored, } \\
\text { translucent }\end{array}$ & Clear, \\
& & transparent \\
\hline
\end{tabular}

and translucency of composite was an undesirable property and not as acceptable as clear, transparent acrylic. ${ }^{10}$ It was noted that none of the patients found fault with the color of composite and offered no preference for the clear acrylic over the tooth-colored composite. This was best expressed by the 4 patients who had previously worn a clear acrylic splint for several years prior to the composite.

In cases of fracture of the composite splint, repair is easily managed by the addition of light-cured composite, which alters the molecular structure and thereby reconstitutes the fracture site. This differs from the repair of an acrylic fracture, which is a temporary "patch." Even when reinforcing pins are used, the acrylic repair site remains weak and is prone to fracture.

One report has suggested that composite was too brittle a material and splints made of composite fractured easily. ${ }^{10}$ Since 1996 , this author has delivered over 200 composite splints and found fractures to occur only when the occlusal thickness was less than $1.50 \mathrm{~mm}$. If not properly constructed or adjusted, excessive occlusal forces over a thin, weak area will cause fracture. All of the composite splints delivered over the past 4 years were accepted by the patients and proved to be effective whether made for TMD patients or for traumatic occlusal habits. 


\section{ACKNOWLEDGMENTS}

Mr. Tom Wise, a dental technician with E.C. Moore Co., Dearborn, Michigan, fabricated all the composite and acrylic bite splints, and E. C. Moore Co. provided all the materials used in this study. The author gratefully acknowledges the advice and direction of Dr. William V. Giannobile of the University of Michigan in reviewing this manuscript.

\section{REFERENCES}

1. Laskin DM. Etiology of pain dysfunction syndrome. $J$ Am Dent Assoc 1969;79:147-153.

2. Ramfjord SP, Ash MM. Occlusion, 3rd ed. Philadelphia: W.B. Saunders Co; 1983:165-167,219-232.

3. Farrar WR. Differentiation of temporomandibular joint dysfunctions to simplify treatment. $J$ Prosthet Dent 1972;28:629-636.

4. Christiansen GJ. Abnormal occlusal conditions: A forgotten part of dentistry. J Am Dent Assoc 1985;126: 1667-1668.

5. Fossell H, Kalso E, Koskela P, Vehmanen R, Puukka P, Alanen P. Occlusal treatments in temporomandibular disorders: A qualitative systematic review of randomized controlled trials. Pain 1999;83:549-560.

6. Okeson JP. Management of Temporomandibular Disorders and Occlusion, 3rd ed. St. Louis: CV Mosby; 1993:474-502.

7. Leib AM. The occlusal bite splint - A non-invasive therapy for occlusal habits and temporomandibular disorders. Compendium Continuing Educ Dent 1996;17: 1081-1090.

8. Serio FG, Hawly CE. Periodontal trauma and mobility: Diagnosis and treatment planning. Dent Clin North Am 1999;43:37-43.

9. Josell SD. Tooth stabilization for orthodontic retention. Dent Clin North Am 1999;43:151-165.

10. Nassif NJ, al-Ghamdi KS. Managing bruxism and temporomandibular disorders using a centric relation occlusal device. Compendium Continuing Educ Dent 1999; 20:1071-1074,1076,1078.

11. Major PW. Use and effectiveness of splint appliance therapy: Review of literature. Cranio 1997;15:161.

12. Capp NJ. Occlusion and splint therapy. Br Dent J 1999; 5:217-222.

13. Wise T. Occlusal preforms and procedure for producing dental splint appliances. US patent $6,082,995$. July 4, 2000.

14. Ash MM, Ramfjord SP. Reflections on the Michigan splint and other intraocclusal devices. J Mich Dent Assoc 1998;80:32-35,41-46.

15. Taubert T. Laboratory procedures for the fabrication of the maxillary occlusal bite plane splint. Dent Clin North Am 1995;39:423-439.

16. Okeson JP. The effects of hard and soft splints on nocturnal bruxism. J Am Dent Assoc 1987;114:788-791.

17. Navarro E, Barghi N, Rey R. Clinical evaluation of maxillary hard and resilient occlusal splints. J Dent Res 1985;64:313-319.
18. Al-Quran FA, Lyons MF. The immediate effect of hard and soft splints on the EMG activity of the masseter and temporalis muscles. J Oral Rehabil 1999;26:559-563.

19. Singh BP, Berry DC. Occlusal changes following use of soft occlusal splints. J Prosthet Dent 1985;54:711715.

20. Cook WD, Beech DR, Tyas MJ. Structure and properties of methacrylate based dental restorative materials. Biomaterials 1985;6:362-368.

21. Puckett AD, Smith R. Method to measure the polymerization shrinkage of light cured composite. J Prosthet Dent 1992;68:56-58.

22. Cook WD, Forrest M, Goodwin AA. A simple method for the measurement of polymerization shrinkage in dental composites. Dent Mater 1999;15:447-449.

Send reprint requests to: Dr. Alden M. Leib, 31400 Northwestern Highway, Suite A, Farmington Hills, MI 483342562. Fax: 248/851-7065; e-mail: Aleib59314@aol.com

Accepted for publication February 9, 2001. 